\title{
十二烷基硫酸钠辅助制备高电容性能多孔碳
}

\author{
焦建超门朱玉金釗彭晓薇金世航张云强* 李梅* \\ (齐鲁工业大学(山东省科学院)材料科学与工程学院 济南 250353)
}

\begin{abstract}
摘要 本工作通过一步水浴法制备高氮/氧含量密胺树脂(MF), 引入阴离子型表面活性剂十二烷基硫酸钠(SDS)改变聚 合物的反应历程, 使进入 SDS 胶束中的三聚氰胺与甲醛在盐酸催化条件下进行聚合反应，高温碳化后成功制备 MF 衍 生多孔碳材料. 对 MF 衍生多孔碳材料分别进行了扫描电镜、比表面积等表征, 结果表明, 其具有多孔互穿网络结构, 比表面积高达 $387.86 \mathrm{~m}^{2} \cdot \mathrm{g}^{-1}$, 且孔径分布适宜 $(3.62 \mathrm{~nm})$. 作为超级电容器 $(\mathrm{SCs})$ 电极材料, 在 $1.0 \mathrm{~A} \cdot \mathrm{g}^{-1}$ 下的比电容值为 $349.6 \mathrm{~F} \cdot \mathrm{g}^{-1}, 20.0 \mathrm{~A} \cdot \mathrm{g}^{-1}$ 时 $\left(254.6 \mathrm{~F} \cdot \mathrm{g}^{-1}\right)$ 仍能维持 $1.0 \mathrm{~A} \cdot \mathrm{g}^{-1}$ 时 $73.0 \%$ 的电容保持率，倍率性能优异. 该样品在 $10.0 \mathrm{~A} \cdot \mathrm{g}^{-1}$ 下 循环 15000 次后的比电容值几乎没有衰减, 循环稳定性能优越. 此研究结果表明 SDS 可辅助提升 MF 衍生多孔碳材料 的电容性能, 发展潜力巨大.

关键词 密胺树脂; 十二烷基硫酸钠; 分级多孔结构; 高氮/氧含量; 高电容性能
\end{abstract}

\section{Preparation of High Capacitive Performance Porous Carbon Assisted by Sodium Dodecyl Sulfate}

\author{
Jianchao Jiao $^{\dagger} \quad$ Yuxin Zhu $^{\dagger} \quad$ Xiaowei Peng Shihang Jin $\quad$ Yunqiang Zhang* Mei Li* \\ (School of Materials Science and Engineering, Qilu University of Technology, Jinan 250353, China)
}

\begin{abstract}
Benefiting from the inducing effect of sodium dodecyl sulfate (SDS) during the polymerization process of melamine and formaldehyde, melamine resin (MF)-derived porous carbon materials with high nitrogen and oxygen content have been synthesized via an annealing-followed water bath method in this work. To study the effect of SDS on the synthesis and properties of MF-derived porous carbon materials, the microstructure and composition of as-prepared samples are characterized by scanning electron microscopy (SEM), nitrogen adsorption/desorption and X-ray photoelectron spectroscopy (XPS). It can be seen from SEM images that sample of the best additive amount (MFC-SDS30) has the interpenetrating network structure, which is conducive to the rapid transfer of electrons and electrolyte ions. Nitrogen adsorption/desorption isotherms indicate that all samples have large specific surface area (SSA) and more micropores/mesopores, which are caused by the pyrolysis of SDS at $700{ }^{\circ} \mathrm{C}$. MFC-SDS30 has the largest SSA $\left(387.86 \mathrm{~m}^{2} \cdot \mathrm{g}^{-1}\right)$ and a suitable pore size distribution $(3.62 \mathrm{~nm})$, which effectively improve the ion diffusion mobility and shorten the ion diffusion pathways. Interestingly, the XPS results show that MFC-SDS30 has high N atom content (15.5 at.\%) and $\mathrm{O}$ atom content (6.5 at.\%) without any additional doped treatment, so the abundant pseudocapacitance is contributed through the rapid N/O atoms redox reaction. Due to the above structural characteristics, MFC-SDS30 exhibits high specific capacitance value $\left(C_{\mathrm{sp}}\right)$ of $349.6 \mathrm{~F} \bullet \mathrm{g}^{-1}$ at $1.0 \mathrm{~A} \cdot \mathrm{g}^{-1}$, and the $C_{\mathrm{sp}}$ $\left(254.6 \mathrm{~F} \bullet \mathrm{g}^{-1}\right)$ at $20.0 \mathrm{~A} \cdot \mathrm{g}^{-1}$ still maintains $73.0 \%$ of that at $1.0 \mathrm{~A} \cdot \mathrm{g}^{-1}$, showing good capacitive performance as electrode material for supercapacitors (SCs). The $C_{\text {sp }}$ of MFC-SDS30 has almost no attenuation after 15000 cycles at $10.0 \mathrm{~A} \cdot \mathrm{g}^{-1}$, which possesses good cycle stability. Besides, the maximum energy density of symmetrical SCs based on MFC-SDS30 is 9.2 $\mathrm{Wh} \cdot \mathrm{kg}^{-1}$ at the power density of $250 \mathrm{~W} \cdot \mathrm{kg}^{-1}$, and the energy density still reaches $4.0 \mathrm{Wh} \cdot \mathrm{kg}^{-1}$ at $5000 \mathrm{~W} \cdot \mathrm{kg}^{-1}$, which is better than many reported carbon materials. Therefore, MF-derived porous carbon materials assisted by SDS can be a promising electrode material for SCs by means of a green and efficient method.
\end{abstract}

Keywords melamine formaldehyde resin; sodium lauryl sulfate; hierarchical porous structure; high nitrogen and oxygen content; high capacitive performance

\section{1 引言}

随着储能技术的快速发展, 超级电容器(SCs)因功
率密度高、充放电速度快、等效串联电阻低、循环寿命 长等优点而备受关注 ${ }^{[1-3]}$. 但不可避免地, 其较低能量密 度极大地限制了 $\mathrm{SCs}$ 作为主要能源的进一步应用, 而电

\footnotetext{
* E-mail: yun_zhang@qlu.edu.cn; lim@qlu.edu.cn; Tel.: 13854137578

$\dagger$ These authors contributed equally to this work.

Received January 12, 2021; published April 13, 2021.
}

Project supported by the International Cooperation Foundation of Qilu University of Technology (QLUTGJHZ2018023), the Innovation Training Program for College Students of Shandong Province in 2020 (No. S202010431115) and the Undergraduate Academic Climbing Program of Qilu University of Technology (Shandong Academy of Sciences).

项目受齐鲁工业大学国际合作基金(QLUTGJHZ2018023)、2020 年山东省大学生创新训练计划项目(No. S202010431115)和齐鲁工业大学(山东省科学 院)本科生学术攀登计划资助. 
极材料的电容性能与工作电压是影响能量密度大小的 关键因素 ${ }^{4]}$. 因此研究者们致力于设计高电容性能的功 能化电极材料, 使其具有较低的电阻, 提高离子传输速 率、电极/电解质有效接触面积和循环稳定性 ${ }^{[5-7]}$. 众所 周知, 碳基材料以其低成本、高导电性、可调谐的孔径 以及优越的物理性能在众多材料中脱颖而出, 但碳材料 的结构需要进一步设计以提高其电容性能 ${ }^{[8-10]}$. 而获得 高比表面积被证明是一种提高材料电容性能的高效方

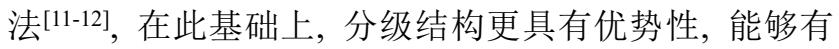
效提升材料的离子可达比表面积和电化学反应的动力 学 [13-14], 离子可达比表面积与孔结构之间的平衡对于提 升碳结构的电容性能也至关重要 ${ }^{[15]}$. 因此介孔、大孔可 以充当电解质离子的储存库以缩短离子传输路径, 从而 电解质离子从介孔、大孔传递到微孔, 大大提高了离子 扩散速率，从而有效改善材料的电容性能和倍率性 能 ${ }^{[16-17]}$. 此外, 由于杂原子掺杂有益于增强质子的供电 子性和碳原子电荷密度而贡献出丰富的赝电容, 采用富 氮有机物为基体材料或引入杂原子对碳材料进行修饰 可以有效提高碳材料的电容性能 ${ }^{[18-19]}$.

以具有特殊两亲性质的表面活性剂作为软模板, 在 设计分级孔结构的碳材料中被证明是一种高效的策 略 ${ }^{[20-22]}$. 例如 $\mathrm{Li}$ 等 ${ }^{[23]}$ 采用阳离子双子表面活性剂戊1,5-双 (二甲基十六基溴化铵)作为软模板合成了形态可 控的介孔中空碳球. 在 $6.0 \mathrm{~mol} \cdot \mathrm{L}^{-1} \mathrm{KOH}$ 电解液中具有 优秀的电化学比电容(在 $0.2 \mathrm{~A} \cdot \mathrm{g}^{-1}$ 时电容值为 240.0 $\left.\mathrm{F} \cdot \mathrm{g}^{-1}\right), 20.0 \mathrm{~A} \cdot \mathrm{g}^{-1}$ 时仍能达到 $161.0 \mathrm{~F} \cdot \mathrm{g}^{-1}$, 具有良好的循 环稳定性(在 $10.0 \mathrm{~A} \cdot \mathrm{g}^{-1}$ 时循环 5000 个周期的电容保持 率为 $92.0 \%$ ). 表面活性剂的润湿及模板作用, 使材料的 综合性能有效地得到提升 ${ }^{[24]}$. 为了获得更好性能的电 极材料, 选择富氮有机物三聚氰胺甲醛树脂(MF)作为 基体材料, 引入表面活性剂 SDS 作为软模板, 获得高氮 含量和分级多孔结构 ${ }^{[25]}$. 其中 $M F$ 树脂中 $C=N$ 键能很 高, 经过高温碳化后碳材料中氮原子热损失较低, 从而 获得高的氮原子含量(15.0 at.\%以上)的树脂碳材料, 保 证了材料与电解质接触界面的润湿性, 发生快速可逆的 氧化还原反应 ${ }^{[26]}$. 阴离子表面活性剂 SDS 在达到临界 胶束浓度 $(\mathrm{CMC})$ 后, 可以形成球形胶束, 在 $\mathrm{MF}$ 制备过 程中可以改变其反应历程, 碳化后可以得到分级多孔结 构的碳材料, 对 MF 基衍生碳材料的电容性能有大幅的 提升.

因此本研究以高氮含量的密胺树脂为基体材料进 行自掺杂, 引入阴离子型表面活性剂 SDS, 以 SDS 胶束 为反应场所, 经过简便的一步水浴法合成了 $\mathrm{MF}$ 衍生碳 材料. 样品 MFC-SDS30 具有良好的分级多孔结构和较 高的比表面积 $\left(387.858 \mathrm{~m}^{2} \cdot \mathrm{g}^{-1}\right)$. 此外, 样品 MFC-SDS30 展示出高比电容值 $\left(0.5 \mathrm{~A} \cdot \mathrm{g}^{-1}\right.$ 时高达 $\left.456.8 \mathrm{~F} \cdot \mathrm{g}^{-1}\right)$ 以及优 异的倍率性能 $\left(20.0 \mathrm{~A} \cdot \mathrm{g}^{-1}\right.$ 时电容值保留了 $1.0 \mathrm{~A} \cdot \mathrm{g}^{-1}$ 时的 $73.0 \%$ ). 最后, 样品 MFC-SDS30 在 $10.0 \mathrm{~A} \cdot \mathrm{g}^{-1}$ 下进行
15000 次充放电循环后，比电容值保留率超过 $100 \%$ ，具 有良好的循环稳定性. 此研究结果表明表面活性剂 SDS 辅助提升 MF 基碳材料的电容性能是一种高效的策略, 绿色温和成本低廉, 作为超级电容器电极材料性能优 异，具有良好的发展前景.

\section{2 结果与讨论}

\section{1 材料表征}

图 1 为样品 MF-0 (a)、MFC-0 (b, c) 和 MF-SDS30 (d)、MFC-SDS30 (e, f) 在不同放大倍数下的 SEM 图. 如 图 1a 所示, 不添加 SDS 时, MF-0 是球径大小不一的, $0.2 \sim 3.0 \mu \mathrm{m}$ 的密胺树脂微球. 如图 $1 \mathrm{~b}$ 所示, 在经过 $700{ }^{\circ} \mathrm{C}$ 的高温处理后, 密胺树脂的微球在高温下熔融流 动, 碳化后形成了块体. 从图 1c 放大图中可以看出, MFC-0 的块体表面有很多褶皱, 没有看出明显的孔洞. 相对应地，添加了 SDS 后得到的密胺树脂微球直径变 小, 许多微球粘结在一起形成了松散的大球, 大球的表 面堆积了很多小的树脂球，如图 1d 所示. 这是由于 SDS 的浓度为 $1.22 \times 10^{-2} \mathrm{~mol} \cdot \mathrm{L}^{-1}$, 远高于其临界胶束浓度 $8.44 \times 10^{-3} \mathrm{~mol} \cdot \mathrm{L}^{-1}$, 在水相中形成了众多的胶束 ${ }^{[27]}$. 而 单体三聚氰胺微溶于水, 水相中微量的三聚氰胺与甲醛 在盐酸催化作用下形成低聚体，这些低聚体是亲油的， 容易进入胶束中去, 胶束中的低聚体之间不断反应使产 物的分子量逐步提高. SDS 的加入改变了缩聚反应的反 应历程，所得到的聚合物的分子量和分子结构也有所不 同, 从图 1d 与图 1a 中可以看出其表面形貌截然不同. 高温处理后, 如图 1e 所示, 呈现出松散的团块, 进一步 放大后发现, 样品表面形成了很多相互贯通的网络状的 孔道, 这些孔道甚至能够渗透到团块的内部, 如图 $1 \mathrm{f}$ 箭 头所示. 这些丰富的孔道使得电解液容易润湿材料的表 面, 同时为电解质离子的快速传输提供了便捷通道.

图 2 分别是样品的 XRD 图谱、Raman 图谱、FTIR 图谱、TGA 曲线, 对材料的结构进行了详细的表征与分 析. 图 $2 \mathrm{a}$ 为添加 SDS 前后样品的 XRD 分析结果, 可以 看出, 样品在 $26.4^{\circ}$ 和 $43.6^{\circ}$ 左右有两个衍射峰, 分别属 于(002)和(100)晶面 ${ }^{[28]}$. 相比较样品 MFC-0, 已添加 SDS 样品的衍射峰强度都有所降低, 加入 SDS 后样品的 结晶度变差. 如图 $2 \mathrm{~b}$ 中的拉曼光谱所示, 样品在 1346 $\mathrm{cm}^{-1}$ (D 带)和 $1582 \mathrm{~cm}^{-1}$ (G 带)附近出现两个特征峰, 分 别与 $\mathrm{sp}^{3}$ 杂化碳和结晶的石墨化 $\mathrm{sp}^{2}$ 碳有关 ${ }^{[29]}, I_{\mathrm{G}} / I_{\mathrm{D}}$ 比值 代表碳化后样品的石墨化程度. 如图 $2 \mathrm{~b}$ 中拉曼图谱所 示, 相对于样品 MFC-0 $\left(I_{\mathrm{G}} / I_{\mathrm{D}}=0.715\right), \mathrm{MFC}-\mathrm{SDS} 20$ $\left(I_{\mathrm{G}} / I_{\mathrm{D}}=0.702\right), \mathrm{MFC}-\mathrm{SDS} 30\left(I_{\mathrm{G}} / I_{\mathrm{D}}=0.679\right)$ 与 MFC$\operatorname{SDS} 40$ 样品 $\left(I_{\mathrm{G}} / I_{\mathrm{D}}=0.670\right)$ 的 $I_{\mathrm{G}} / I_{\mathrm{D}}$ 比值都有所降低, 这一 结果说明加入 SDS 的材料石墨化程度降低, 无序程度 增加, 与 XRD 结果一致. 这可能是由于加入 SDS 后的 样品, 碳化过程中 SDS 的热解使材料产生了较多的微 

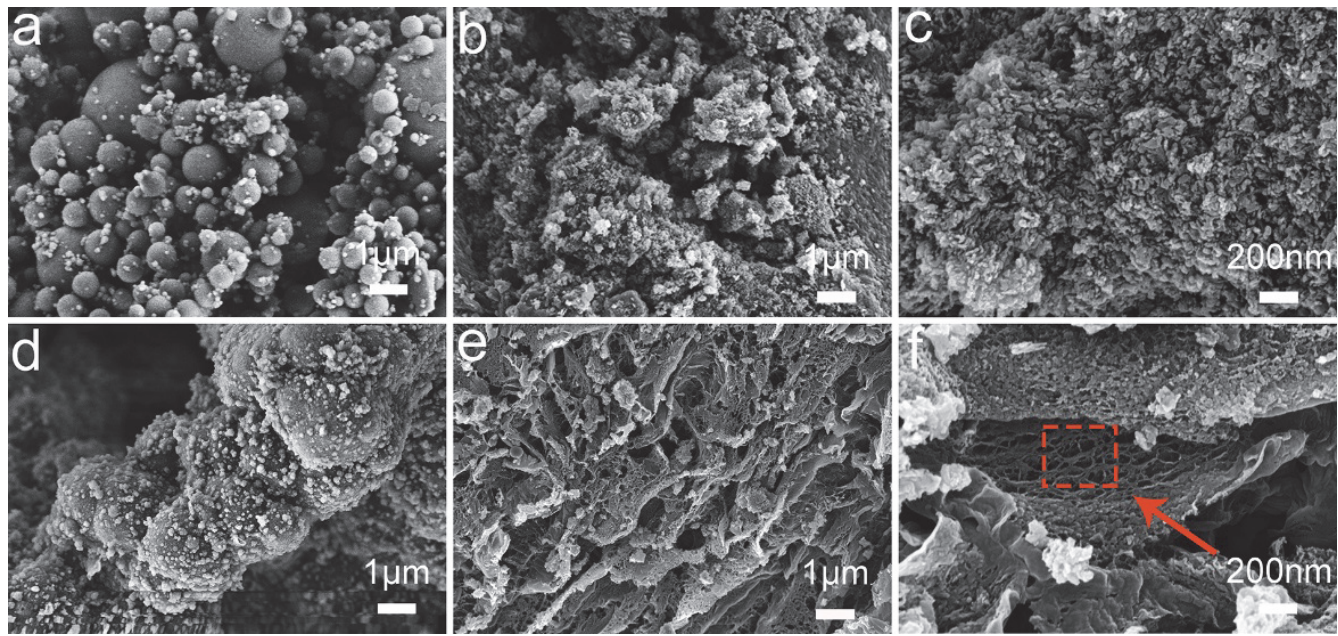

图 1 样品的 SEM 照片: (a) MF-0, (b, c) MFC-0, (d) MF-SDS30, (e, f) MFC-SDS30

Figure 1 SEM images of samples: (a) MF-0, (b, c) MFC-0, (d) MF-SDS30 and (e, f) MFC-SDS30
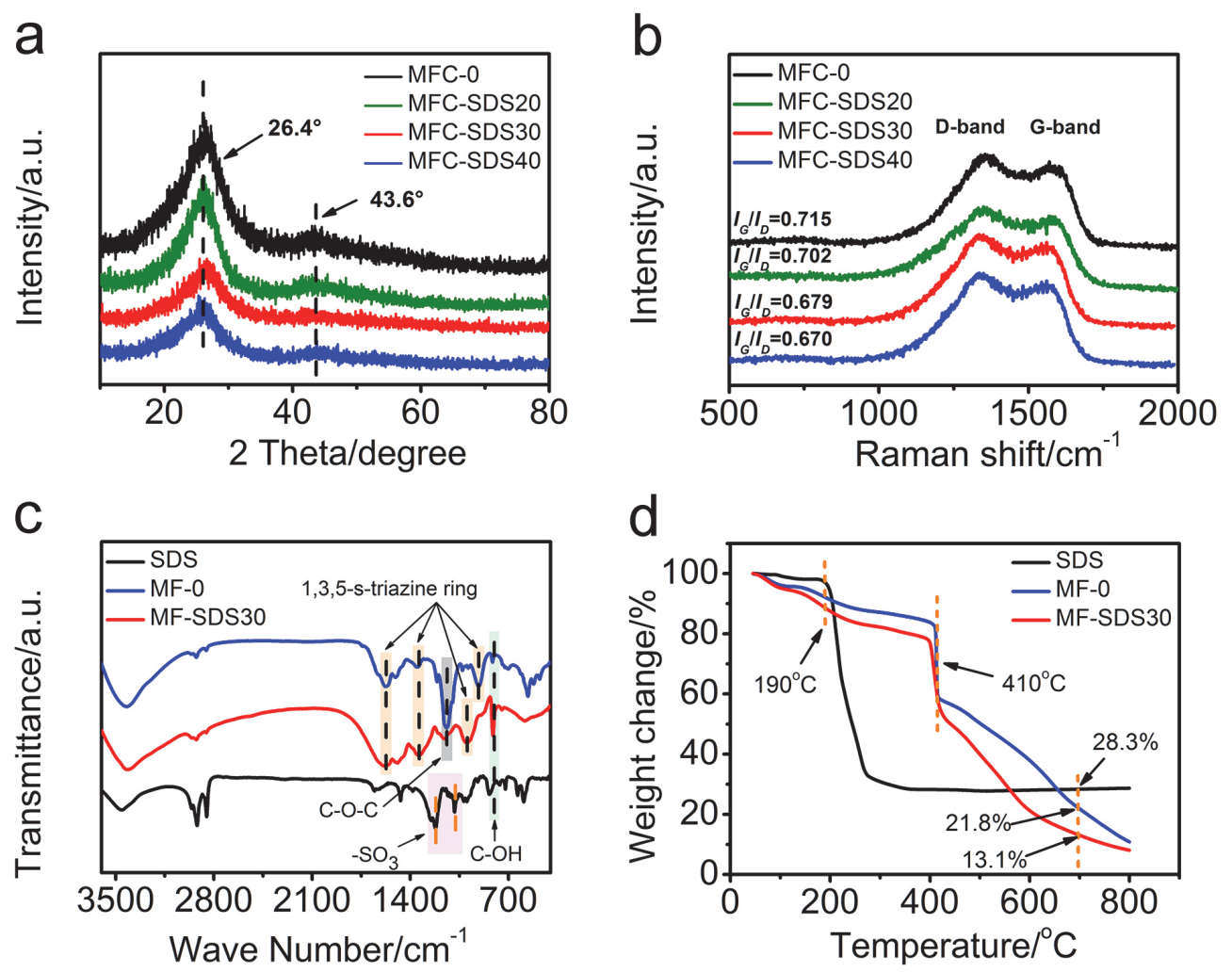

图 2 (a) XRD 谱图, (b) Raman 谱图, (c) FTIR 谱图, (d) 热重曲线

Figure 2 (a) XRD spectra, (b) Raman spectra, (c) the FTIR spectra, (d) TGA curves of samples

孔和介孔，更重要的是在碳化后引入了多孔网络结 构 ${ }^{[30]}$. 我们将在后面的测试中说明样品在添加 SDS 前 后孔道及比表面积的变化.

为了清楚地显示它们的分子结构和化学成分的差 异, 我们用 FTIR 光谱分析了 SDS、MF-SDS30 和 MF-0 样品(图 2c), 样品 MF-SDS30 的红外谱图与 MF-0 相比 有明显的变化. 在 $1130 \mathrm{~cm}^{-1}$ 左右处的峰属于-C-O-C-基 团的伸缩振动, 说明微量的 SDS 残留在聚合物中. 在
1619、 $1490 \mathrm{~cm}^{-1}$ 处的吸收峰分别属于 $-\mathrm{C}=\mathrm{N},-\mathrm{N}=\mathrm{N}$-等 双键的伸缩振动的特征峰, 代表了三嗪环的存在 ${ }^{[20]}$, 在 1079、1118、1220 $\mathrm{cm}^{-1}$ 三处的吸收峰是 $-\mathrm{SO}_{3}$ 基团的伸 缩振动引起的. 由于 SDS 对 MF 树脂微球的调控作用, 碳材料的微观结构发生了变化, 图 2d 中通过样品质量 残留率与温度的关系展示了样品 SDS、MF-SDS30 和 MF-0 的热稳定性. SDS 在 $190{ }^{\circ} \mathrm{C}$ 左右发生了急剧热失 重, 结构被破坏, 低于 MF-SDS30 和 MF-0 分解温度 
$\left(410{ }^{\circ} \mathrm{C}\right)$. 而在温度为 $700{ }^{\circ} \mathrm{C}$ 时, 样品 $\mathrm{MF}-\mathrm{SDS} 30$ 的质 量保持率为 $13.1 \%$, 低于 MF-0 的质量保持率(21.8\%), 这是由于 SDS 改变了密胺树脂的反应历程, 结构发生 改变, 键能变化, 热稳定性变差 ${ }^{[31]}$.

运用 $\mathrm{N}_{2}$ 吸脱附的方法对样品 MFC-0, MFC-SDS20, MFC-SDS30, MFC-SDS40 的孔隙结构做了进一步的表 征. 图 3 为制备样品的 $\mathrm{N}_{2}$ 吸/脱附等温曲线图(图 3a)和 孔径分布曲线(图 3b), 表 1 为添加 SDS 前后样品的比表 面积和孔隙结构数据. 如图 3a 所示, 添加 SDS 的样品的 $\mathrm{N}_{2}$ 吸/脱附等温曲线在 $0<p / p_{0}<0.03$ 有一段急剧上升的 部分, 属于典型的 I 型等温线, 表明材料的微孔孔隙结 构比较丰富. 另外, 在 $0.45<p / p_{0}<0.90$ 处属于典型的 IV 型等温线, 具有明显的回滞环, 证明了材料中有较多 的介孔存在 ${ }^{[32-33]}$. 从表 1 中孔结构数据可以得知, 未添 加 SDS 时, 样品 MFC-0 的 $S_{\mathrm{BET}}$ 为 $82.18 \mathrm{~m}^{2} \cdot \mathrm{g}^{-1}$, 添加 SDS 后, MFC-SDS20, MFC-SDS30 和 MFC-SDS40 分别 为 $321.50,387.86$ 和 $251.05 \mathrm{~m}^{2} \bullet \mathrm{g}^{-1}, S_{\mathrm{BET}}$ 都得到了不同程 度的提高, 尤其是样品 MFC-SDS30 中的介孔 $S_{\mathrm{BET}}$ $\left(283.03 \mathrm{~m}^{2} \cdot \mathrm{g}^{-1}\right)$ 和孔容 $\left(0.29 \mathrm{~cm}^{3} \cdot \mathrm{g}^{-1}\right)$ 都明显高于样品 MFC-0、MFC-SDS20 和 MFC-SDS40, 这是由于密胺树 脂中大量残留的 SDS 是小分子化合物, 在碳化过程中 发生绝大部分的热损失, 在材料中留下缺陷, 得到大量 的微/介孔, 电解质离子在介孔中的扩散速率较快, 由介 孔进入微孔的扩散路径缩短, 故多级孔结构中微/介孔 比表面积的大幅提升会大大提高电解质的转移速率, 有 益于材料比电容的提高 ${ }^{[34]}$.

\section{a}

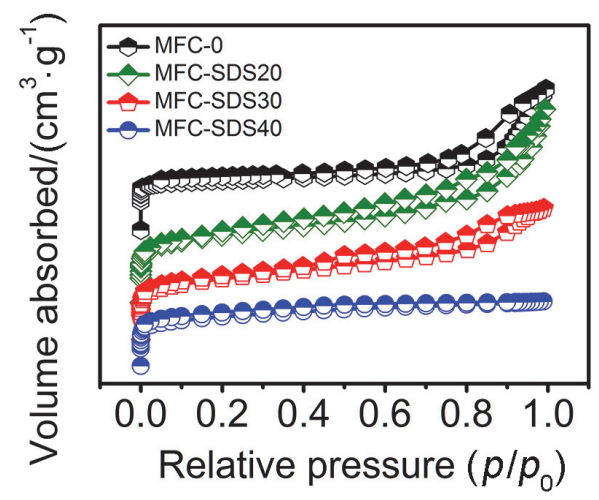

通过 XPS 对样品 MFC-0 和 MFC-SDS30 的元素组 成以及不同原子结合状态进行分析，如图 4 及表 2 所示. 图 4 中 C 1s、N 1s 和 O 1s 的峰值分别位于 284.09 $286.98 \mathrm{eV} 、 397.53 \sim 403.90 \mathrm{eV}$ 和 $530.28 \sim 533.83 \mathrm{eV}$ 之 间，图 $4 \mathrm{a} \sim 4 \mathrm{c}$ 给出了 $\mathrm{MFC}-0$ 中 $\mathrm{C} 1 \mathrm{~s} 、 \mathrm{~N} 1 \mathrm{~s}$ 和 $\mathrm{O} 1 \mathrm{~s}$ 的不 同结合态，图 $4 \mathrm{~d} \sim 4 \mathrm{f}$ 表示的是 MFC-SDS30 的 C 1s、N 1s 和 $\mathrm{O} 1 \mathrm{~s}$ 的分峰情况. 添加 SDS 前后, 不同结合态 C $1 \mathrm{~s}$ 、 $\mathrm{N} 1 \mathrm{~s}$ 和 $\mathrm{O} 1 \mathrm{~s}$ 含量的变化情况如图 $4 \mathrm{~g} \sim 4 \mathrm{i}$ 所示. 图 $4 \mathrm{~g}$ 中 $\mathrm{C} 1 \mathrm{~s}$ 能谱显示了样品中含有不同结合态的 $\mathrm{C}-\mathrm{C}, \mathrm{C}=\mathrm{N}$, $\mathrm{C}-\mathrm{O} / \mathrm{C}-\mathrm{N}$. 其中 $284.30 \mathrm{eV}$ 处的 $\mathrm{C}-\mathrm{C}$ 含量从 16.95 at.\%增加至 40.00 at.\%, 这一变化是由于 SDS 的加入改 变了聚合反应的场所，得到了结构不同的聚合物，聚合 物碳化后保留了更多的 $\mathrm{C}-\mathrm{C}$ 单键，替代了 $\mathrm{C}-\mathrm{O} / \mathrm{C}-\mathrm{N}$ 键的位置, 这也是导致 $\mathrm{C}-\mathrm{O} / \mathrm{C}-\mathrm{N}$ 键含量大幅降低的 原因. 图 $4 \mathrm{~h}$ 中两种样品的 $\mathrm{N} 1 \mathrm{~s}$ 能谱在 $403.90 \mathrm{eV}(\mathrm{N}-\mathrm{Q})$ 、 $399.86 \mathrm{eV}(\mathrm{N}-5)$ 和 $397.53 \mathrm{eV}(\mathrm{N}-6)$ 的结合能也有明显变 化. 其中 N-5 峰所代表的是吡咯氮和石墨氮的叠加峰, 其含量由 3.73 at. \%提高至 8.04 at.\%, 有助于材料电容性 能的提升 ${ }^{[35]}$. 此外, 在图 $4 \mathrm{i}$ 中 $\mathrm{O} 1 \mathrm{~s}$ 能谱中分为 $\mathrm{C}-\mathrm{O}$ 、 $\mathrm{C}-\mathrm{OH} / \mathrm{C}-\mathrm{O}-\mathrm{C}$ 和 $\mathrm{C}-\mathrm{N}=\mathrm{O} / \mathrm{C}=\mathrm{O}, 532.41 \mathrm{eV}$ 处的 $\mathrm{C}-\mathrm{OH} / \mathrm{C}-\mathrm{O}-\mathrm{C}$ 的含量由 1.48 at.\%增加至 4.41 at. $\%$, 这是因为反应历程的改变使 MFC-SDS30 中 $\mathrm{O}$ 的结合能 形态发生了很大的变化, 相较于 MFC-0 结构中来说 MFC-SDS30 中 $\mathrm{C}-\mathrm{OH} / \mathrm{C}-\mathrm{O}-\mathrm{C}$ 含量增多, 替代了 $\mathrm{C}-$ $\mathrm{N}=\mathrm{O} / \mathrm{C}=\mathrm{O}$ 键的位置, 引起 $\mathrm{C}-\mathrm{N}=\mathrm{O} / \mathrm{C}=\mathrm{O}$ 含量的降 低.

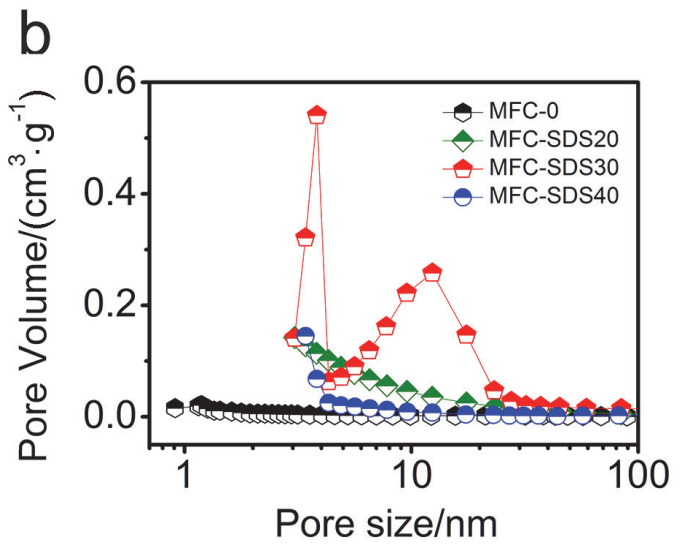

图 3 (a) 样品的氮气吸附/解吸等温线, (b) 样品的孔径分布曲线

Figure 3 (a) $\mathrm{N}_{2}$ adsorption/desorption isotherms, (b) pore size distribution for samples

表 1 系列样品的孔结构数据

Table 1 Pore textural data of samples

\begin{tabular}{ccccccc}
\hline Sample & $\begin{array}{c}S_{\mathrm{BET}}{ }^{a} / \\
\left(\mathrm{m}^{2} \cdot \mathrm{g}^{-1}\right)\end{array}$ & $\begin{array}{c}S_{\text {micro }}{ }^{b} \\
\left(\mathrm{~m}^{2} \cdot \mathrm{g}^{-1}\right)\end{array}$ & $\begin{array}{c}S_{\text {mesomacro }}{ }^{c} \\
\left(\mathrm{~m}^{2} \cdot \mathrm{g}^{-1}\right)\end{array}$ & $\begin{array}{c}V_{\text {tot }}{ }^{\prime} / \\
\left(\mathrm{cm}^{3} \cdot \mathrm{g}^{-1}\right)\end{array}$ & $\begin{array}{c}V_{\text {micro }}{ }^{e} \\
\left(\mathrm{~cm}^{3} \cdot \mathrm{g}^{-1}\right)\end{array}$ & $\begin{array}{c}\text { Average pore size/ } \\
\mathrm{nm}\end{array}$ \\
\hline MFC-0 & 82.18 & 14.14 & 68.04 & 0.18 & 0.01 & 13.36 \\
MFC-SDS20 & 321.50 & 241.20 & 80.30 & 0.21 & 0.19 & 2.58 \\
MFC-SDS30 & 387.86 & 283.03 & 104.83 & 0.29 & 0.26 & 3.62 \\
MFC-SDS40 & 251.05 & 231.47 & 19.58 & 0.14 & 0.12 & 2.23 \\
\hline
\end{tabular}

${ }^{a} S_{\mathrm{BET}}$ is specific surface area by multiple BET method; ${ }^{b} S_{\text {micro }}$ is micropore surface area; ${ }^{c} S_{\text {meso/macro }}$ is mesopore and macropore surface area; ${ }^{d} V_{\text {tot }}$ is total volume; ${ }^{e} V_{\text {micro }}$ is micropore volume. 
a
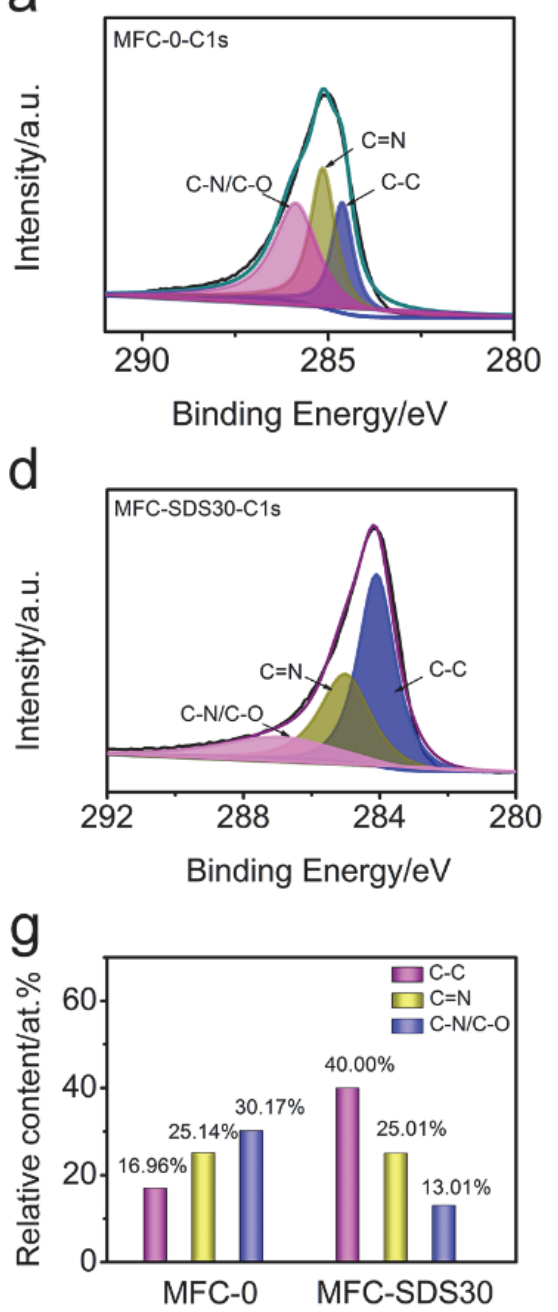

b

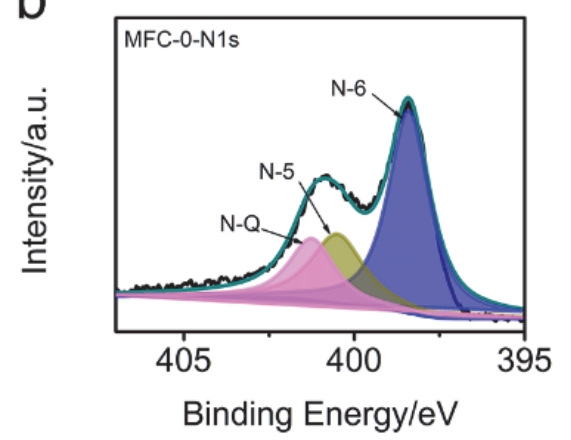

e
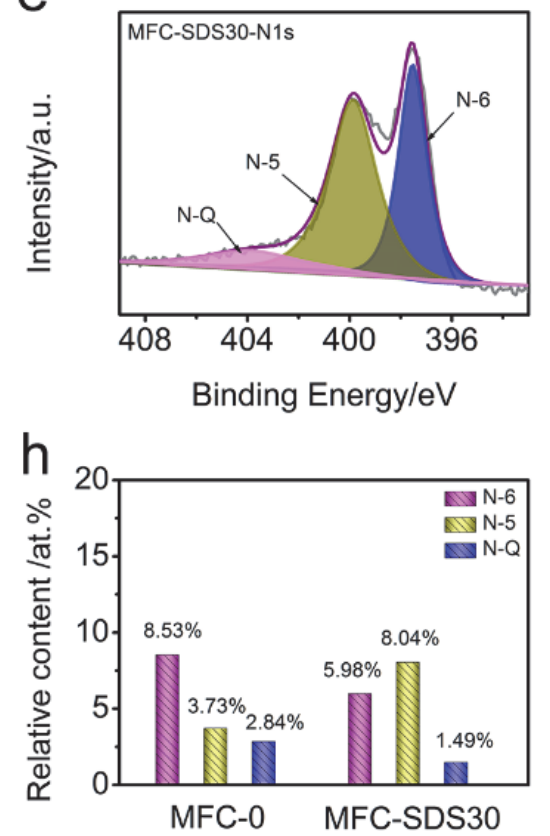

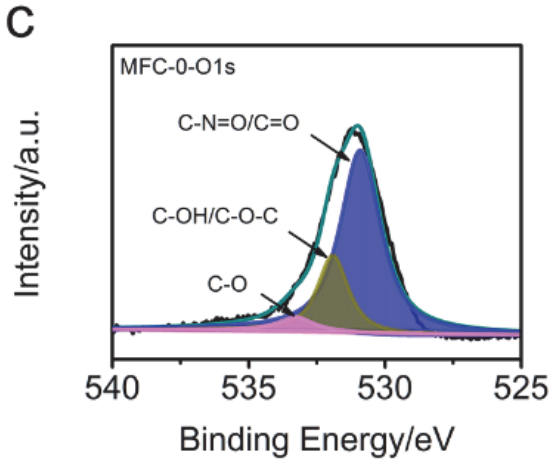

f
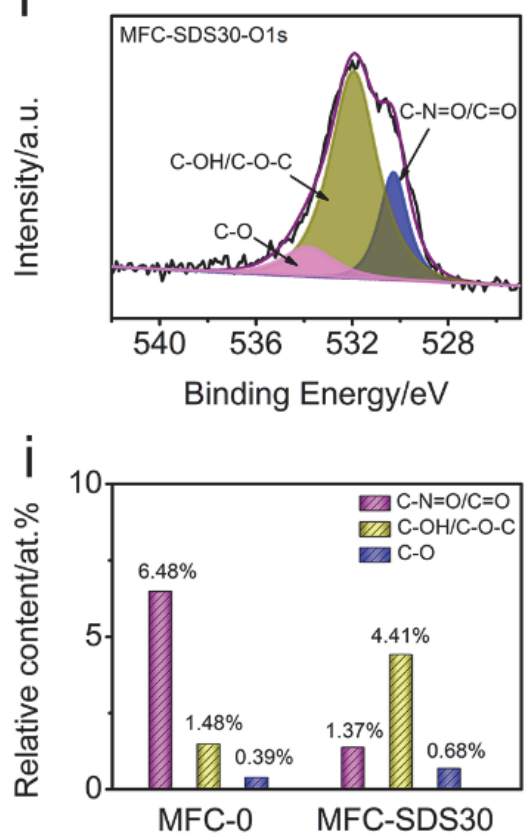

图 4 样品 MFC-0 的高分辨率 XPS 扫描(a) C 1s, (b) N 1s, (C) O 1s 和样品 MFC-SDS30 高分辨率 XPS 扫描 (d) C 1s, (e) N 1s, (f) O 1s, (g i) 相对原 子含量

Figure 4 High-resolution XPS scans for (a) C 1s, (b) N 1s, (c) O 1s of the MFC-0 and (d) C 1s, (e) N 1s, (f) O 1s of the MF-SDS30, (g i) relative atom contents in the samples

表 2 样品 MFC-SDS30 和 MFC-0 的元素原子比

Table 2 Elemental atomic ratio of MFC-SDS30 and MFC-0

\begin{tabular}{cccc}
\hline Sample & C/at.\% & N/at.\% & O/at.\% \\
\hline MFC-SDS30 & 78.0 & 15.5 & 6.5 \\
MFC-0 & 76.0 & 15.1 & 8.9 \\
\hline
\end{tabular}

\section{2 电化学性能分析}

在三电极体系中, 在 $2.0 \mathrm{~mol} \cdot \mathrm{L}^{-1} \mathrm{H}_{2} \mathrm{SO}_{4}$ 电解液中对 样品 MFC-0, MFC-SDS20, MFC-SDS30, MFC-SDS40 分 别进行测试, 得到图 5 的电化学性能图. 如图 5a 所示, MFC-SDS30 的 CV 曲线电压范围为 $-0.3 \sim 0.7 \mathrm{~V}$. 在双 电层电容与起源于氮、氧等杂原子的赝电容的相互作用 下, 样品 MFC-SDS30 的 CV 曲线围绕的面积最大, 代表 具有最高的质量比电容值 $\left(C_{\mathrm{sp}}\right)^{[36]}$. 在图 $5 \mathrm{~b}$ 中, 电流密度 为 $1.0 \mathrm{~A} \cdot \mathrm{g}^{-1}$ 时的 $\mathrm{GCD}$ 曲线表明, 所有曲线均为规则等 腰三角形, 具有良好可逆充放电特性, 材料的倍率性能 良好 [37]. 值得注意的是, 在相同电流密度下, MFC-SDS30 的恒流充放电时间是所有试样中最长的,
这说明了其具有最高的 $C_{\mathrm{sp}}$, 与 $\mathrm{CV}$ 曲线的结论一致, 这 一点在图 $5 \mathrm{~d}$ 中也可以明显看出. 根据公式(1) ${ }^{[38]}$ 计算得 出, 在电流密度为 $1.0 \mathrm{~A} \cdot \mathrm{g}^{-1}$ 时, 样品 MFC- 0 , MFC-SDS20, MFC-SDS30, MFC-SDS40 的 $C_{\mathrm{sp}}$ 分别达到 $190.1,256.3,349.6,246.8 \mathrm{~F}^{\circ} \mathrm{g}^{-1}$. 相对于样品 MFC-0, 添 加了不同量 SDS 样品的 $C_{\mathrm{sp}}$ 都有很大程度的提升, 其中 $0.30 \mathrm{~g}$ SDS 添加量时, 样品的比电容值提升的最为明显. 从图 $5 \mathrm{c}$ 中的 Nyquist 图研究了各个电极材料在 $10^{5} \sim 10^{-2}$ $\mathrm{Hz}$ 开路电位幅值为 $10 \mathrm{mV}$ 时的电化学反应过程. 相对 于样品 MFC-0, 添加不同量 SDS 的样品阻抗都有一定 程度的降低, 其中 MFC-SDS30 电极在 Nyquist 图中高频 区下的半圆直径最小, 代表样品的电荷转移电阻最小, 低频区下最大的直线斜率代表样品具有较小的扩散电 阻, 电解液离子的扩散速率加快, 因此电容性能较优 异 ${ }^{[39-40]}$. 在图 5d 中, 不仅可以直观地看出添加 SDS 后样 品的电容性能优势, 还可以观察到其优异的倍率性能. 
样品 MFC-0, MFC-SDS20, MFC-SDS30, MFC-SDS40 在 电流密度从 $1.0 \mathrm{~A} \cdot \mathrm{g}^{-1}$ 增加到 $10.0 \mathrm{~A} \cdot \mathrm{g}^{-1}$ 时, 倍率性能分 别为 $62.6 \%, 82.0 \%, 73.0 \%$ 以及 $78.5 \%$. 并且在电流密度 为 0.2 和 $1.0 \mathrm{~A} \cdot \mathrm{g}^{-1}$ 时, MFC-SDS30 的 $C_{\mathrm{sp}}$ 可以达到 456.8 和 $349.6 \mathrm{~F} \cdot \mathrm{g}^{-1}$, 在 $20.0 \mathrm{~A} \cdot \mathrm{g}^{-1}$ 时的 $C_{\mathrm{sp}}\left(254.6 \mathrm{~F} \cdot \mathrm{g}^{-1}\right)$ 保留了 $1.0 \mathrm{~A} \cdot \mathrm{g}^{-1}$ 时 $C_{\mathrm{sp}}$ 的 $73.0 \% .0 .30 \mathrm{~g} \mathrm{SDS}$ 添加量的样品性能 达到最佳值, 是材料中石墨化程度和活性位点数目相平 衡的结果, 且样品 MFC-SDS30 中微/介孔数量明显高于 其他样品, 材料的离子可达比表面积大幅增加. 介孔可 以储存更多的电解液离子, 且丰富的微孔结构缩短了离 子扩散路径, 因而得到理想的倍率性能, 在高电流密度 下仍具有较高的比电容值 ${ }^{[41-42]}$.

如图 5e, 5f 所示, 对 MFC-SDS30 在三电极系统中进 行了详细的测试. 如图 5e 所示, MFC-SDS30 的 CV 曲线 电位范围为 $-0.3 \sim 0.7 \mathrm{~V}$, 当扫描速率为 $10 \sim 100$ $\mathrm{mV} \cdot \mathrm{s}^{-1}, \mathrm{MFC}-\mathrm{SDS} 30$ 的所有 CV 曲线形状略微偏离矩形, 这是 $\mathrm{N} / \mathrm{O}$ 杂原子贡献出的赝电容与 $\mathrm{C}$ 原子的双电层电 容共同作用的结果 ${ }^{[43]}$. 图 $5 \mathrm{f}$ 展现了 MFC-SDS30 在 $0.2 \sim 20.0 \mathrm{~A} \cdot \mathrm{g}^{-1}$ 时的 GCD 曲线, 即使在 0.2 和 $20.0 \mathrm{~A} \cdot \mathrm{g}^{-1}$ 的电流密度下, 所有的充放电图形都非常规整, 呈现出 等腰三角形的曲线. 这得益于 MFC-SDS30 的分级多孔 结构特征和较大的离子可达比表面积, 使电解液离子在 充放电过程中充分接触电极材料, N/O 杂原子进行快速 的氧化还原反应提供了可观的赝电容, 以及 $\mathrm{C}$ 原子固有 的双电层电容共同作用得到了优异的电容性能及倍率 性能 ${ }^{[44]}$.
为了进一步测量电极材料的循环稳定性, 将 MFC-SDS30 在电流密度为 $10.0 \mathrm{~A} \cdot \mathrm{g}^{-1}$ 的情况下重复充 放电 15000 次, 结果如图 6a 所示. 图 6a 中的插图显示 出第一个和最后一个充放电图形的形状几乎一致. 经过 15000 次充放电试验, 材料 MFC-SDS30 循环后的电容 值几乎没有衰减, 循环寿命较长. 由于材料具有丰富的 分级多孔和互穿网络结构, 材料的离子传输通道大大缩 短, 以及高的氮、氧杂原子保留率有利于材料吸附电解 液离子, 进一步改善材料的亲疏水性质，使材料润湿性 增强, 并且有利于增强电解液离子在材料微孔、介孔结 构中的传输 ${ }^{[45-46]}$. 基于以上结构特点, 经过长久的充放 电后, 电解质离子与电极材料深度充分接触, 电容值几 乎不衰减.

由于两电极体系更能真实地反映出实际的工作情 况, 基于样品 MFC-SDS30 组装成对称型超级电容器在 $2.0 \mathrm{~mol} \cdot \mathrm{L}^{-1} \mathrm{H}_{2} \mathrm{SO}_{4}$ 电解液中进行测试. 如图 $6 \mathrm{~b}$ 所示, 在 不同的扫描速率下的 $\mathrm{CV}$ 曲线更加偏离矩形, 噟电容作 用明显. 如图 6c 所示, 基于 MFC-SDS30 的对称性超级 电容器器件的 GCD 曲线十分规整, 在充放电过程中离 子响应速度快, 具有优异的可逆充放电特性 ${ }^{[47]}$. 从图 $6 \mathrm{~d}$ 中可以看出电极材料在高频率下具有较小的半圆直径, 低频率下具有斜率较大的直线, 都表明了材料较低的电 荷转移阻抗和扩散电阻, 材料本身丰富的 $\mathrm{N} 、 \mathrm{O}$ 杂原子 含量以及丰富的微孔、介孔，增强了离子和电子在电极 和电极/电解质界面的传输动力学 ${ }^{[48-49]}$. 如图 $6 \mathrm{e}$ 所示, MFC-SDS30 展示良好的电容性能及倍率性能, 在 0.5 a

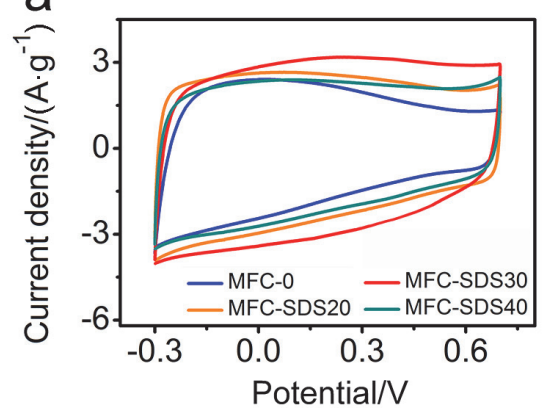

d

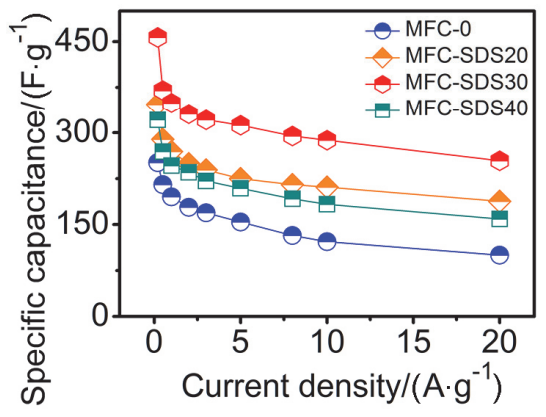

b

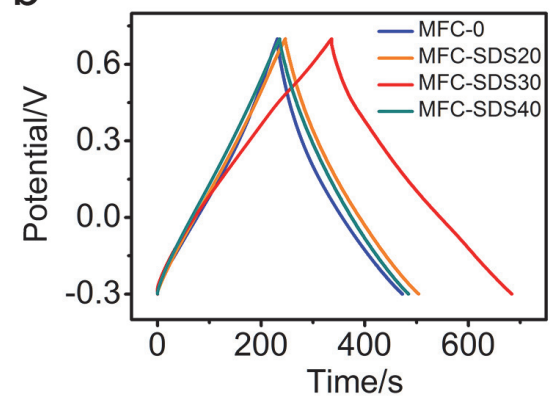

e

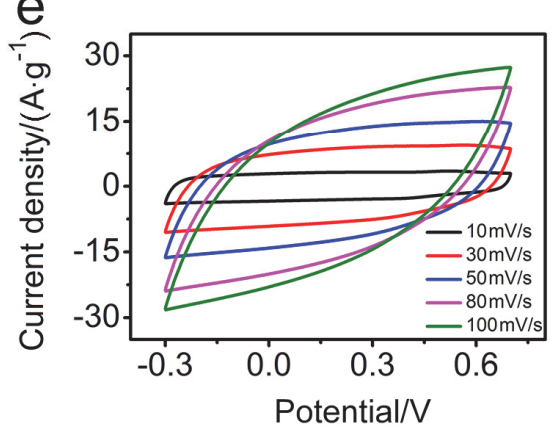

C

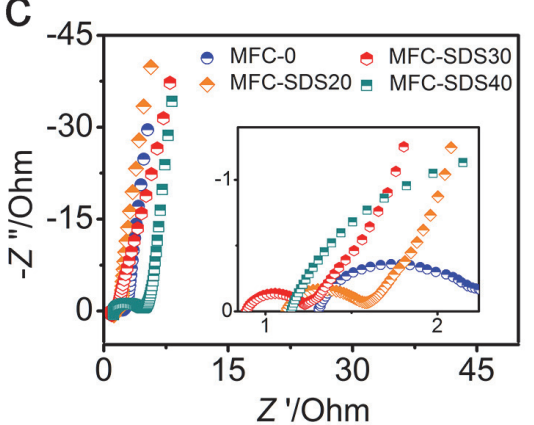

$\mathrm{f}$

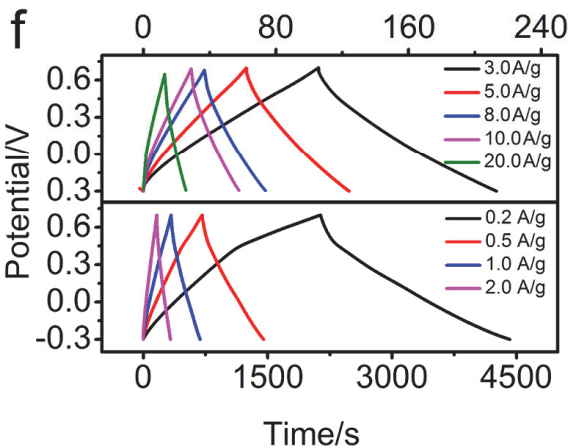

图 5 样品的电化学性能图: (a) 扫描速率为 $10 \mathrm{mV} \cdot \mathrm{s}^{-1}$ 时的 $\mathrm{CV}$ 曲线, (b) 电流密度为 $1.0 \mathrm{~A} \cdot \mathrm{g}^{-1}$ 时的 $\mathrm{GCD}$ 曲线, (c) Nyquist 曲线, (d) 不同电流密度 下的 $C_{\mathrm{sp}}$ 值. MFC-SDS30 的电化学性能图: (e) 扫描速率为 $10 \sim 100 \mathrm{mV} \cdot \mathrm{s}^{-1}$ 的 CV 曲线, (f) 在电流密度 $0.2 \sim 20.0 \mathrm{~A} \cdot \mathrm{g}^{-1}$ 下的 GCD 曲线

Figure 5 Electrochemical performance of samples: (a) CV curves at $10 \mathrm{mV} \cdot \mathrm{s}^{-1}$, (b) GCD curves at $1.0 \mathrm{~A} \cdot \mathrm{g}^{-1}$, (c) Nyquist plots, (d) the $C_{\mathrm{sp}}$ at different current densities. Electrochemical performance of MFC-SDS30: (e) CV curves at $10 \sim 100 \mathrm{mV} \cdot \mathrm{s}^{-1}$, (f) $\mathrm{GCD}$ curves at $0.2 \sim 20.0 \mathrm{~A} \cdot \mathrm{g}^{-1}$ 
$\mathrm{A} \cdot \mathrm{g}^{-1}$ 时, 对称型超级电容器的电容值可以达到 66.0 $\mathrm{F} \cdot \mathrm{g}^{-1}$, 在 $10.0 \mathrm{~A} \cdot \mathrm{g}^{-1}$ 时, 比电容值仍能达到 $28.3 \mathrm{~F} \cdot \mathrm{g}^{-1}$, 保留了 $1.0 \mathrm{~A} \cdot \mathrm{g}^{-1}$ 时的 $44.7 \%$. 图 $6 f$ 表明基于 MFC-SDS30 的对称型超级电容器在不同的电流密度下, 充放电曲线都显示出规整的等腰三角形, 具有优异的可 逆充放电特性 ${ }^{[50]}$. 如图 6f 所示, 我们由公式 $(2 \sim 4)^{[51-53]}$ 计算了基于 MFC-SDS30 对称电极超级电容器的 Ragone 图, 在功率密度为 $250 \mathrm{~W} \cdot \mathrm{kg}^{-1}$ 时对称型 $\mathrm{SCs}$ 的最大能量 密度为 $9.2 \mathrm{Wh} \cdot \mathrm{kg}^{-1}$, 在 $5000 \mathrm{~W} \cdot \mathrm{kg}^{-1}$ 时, 还能保持 4.0 $\mathrm{Wh} \cdot \mathrm{kg}^{-1}$ 的能量密度, 具有巨大的发展潜力. 综上所述, 本工作为分级多孔碳材料的制备提供了一种简便易行 的方法, 显示出作为具有优良电化学性能的 MF 基衍生 碳电极材料在超级电容器领域的广阔发展前景.

$$
\begin{aligned}
& C_{\mathrm{sp}}=I_{1} \times \Delta t_{1} /\left(m_{1} \times \Delta V_{1}\right) \\
& C_{\text {cell }}=I_{2} \times \Delta t_{1} /\left(m_{2} \times \Delta V_{2}\right) \\
& E_{\text {cell }}=C_{\text {cell }} \times \Delta V_{2}^{2} / 7.2 \\
& P_{\text {cell }}=3600 \times E_{\text {cell }} / \Delta t_{2}
\end{aligned}
$$

其中 $I_{1}$ 与 $I_{2}(\mathrm{~A})$ 代表电流, $\Delta t_{1}$ 与 $\Delta t_{2}$ 放电时间, $\Delta V_{1}$ 和 $\Delta V_{2}$ 是根据材料特性设置的电压差 $(\mathrm{V}), m_{1}$ 是涂覆在集流体 上活性物质的质量 $(\mathrm{g}), m_{2}$ 是对称型 $\mathrm{SCs}$ 中活性物质的总 质量 $(\mathrm{g}), C_{\mathrm{sp}}$ 与 $C_{\text {cell }}$ 代表质量比电容值 $\left(\mathrm{F} \cdot \mathrm{g}^{-1}\right), E_{\text {cell }}$ 与 $P_{\text {cell }}$ 分别代表对称型 $\mathrm{SCs}$ 的能量密度 $\left(\mathrm{Wh} \cdot \mathrm{kg}^{-1}\right)$ 与功率密度 $\left(\mathrm{W} \cdot \mathrm{kg}^{-1}\right)$.
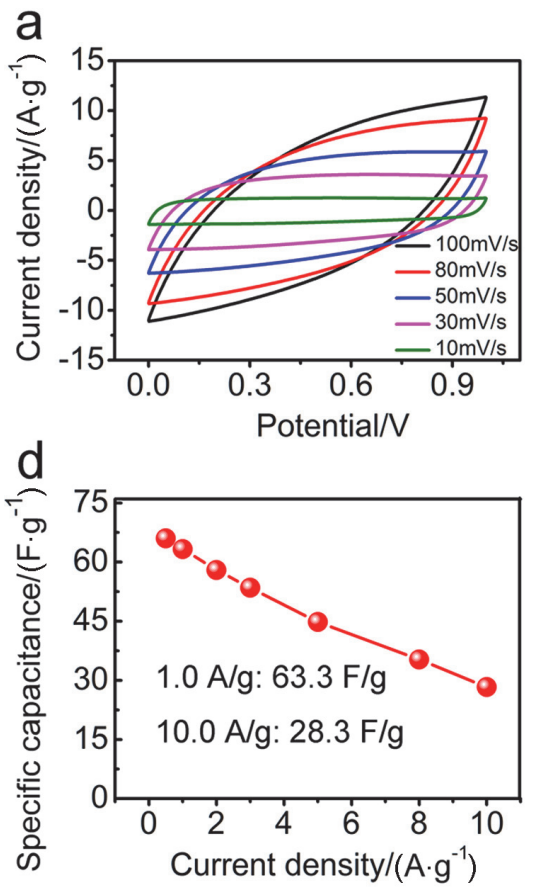

b

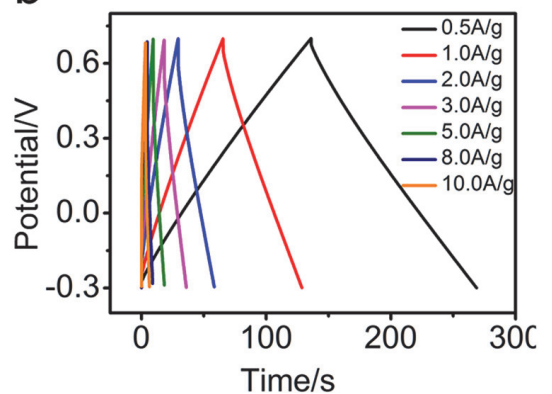

e

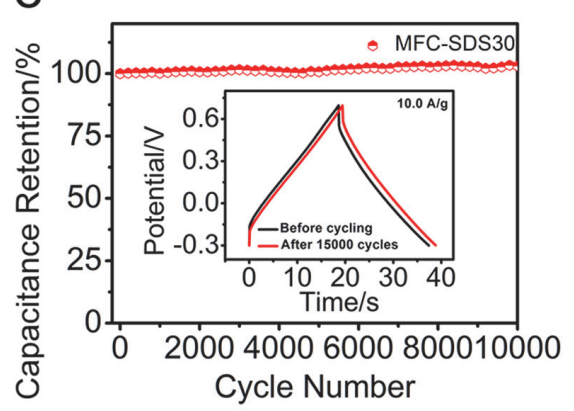

\section{3 结论}

综上所述, 以阴离子表面活性剂 SDS 为软模板, 改 变了密胺树脂的聚合历程, 高温碳化后的 MFC-SDS30 具有分级多孔结构和互穿网络结构, MFC-SDS30 具有 较大的比表面积 $\left(387.86 \mathrm{~m}^{2} \cdot \mathrm{g}^{-1}\right)$ 和高 $\mathrm{N}$ 原子含量 $(15.5$ at. $\%$ )、 $\mathrm{O}$ 原子含量(6.5 at.\%). 基于以上结构特征，材料 MFC-SDS30 用作超级电容器电极材料时展现出了优异 的电化学性能, 在 $0.2 \mathrm{~A} \cdot \mathrm{g}^{-1}$ 下的比电容值为 $456.8 \mathrm{~F} \cdot \mathrm{g}^{-1}$, 且在 $20.0 \mathrm{~A} \cdot \mathrm{g}^{-1}$ 的条件下仍能保持 $254.6 \mathrm{~F} \cdot \mathrm{g}^{-1}$, 保留 1.0 $\mathrm{A} \cdot \mathrm{g}^{-1}$ 时的 $73.0 \%$, 倍率性能出色. 在 $10.0 \mathrm{~A} \cdot \mathrm{g}^{-1}$ 的电流 密度下进行 15000 次充放电循环后, 比电容值几乎没有 衰减, 具有优秀的循环稳定性能. 因此, 通过引入 SDS 绿色高效地提高了密胺树脂基分级多孔碳材料的电化 学性能, 这是一种极具发展前景的超级电容器电极材 料，对于进一步扩大密胺树脂基分级多孔碳材料在能源 领域中的应用具有重要的研究意义.

\section{4 实验部分}

\section{1 复合材料的制备}

首先将 $0.30 \mathrm{~g} \mathrm{SDS}$ 加入盛有 $80.0 \mathrm{~mL}$ 去离子水的三 口烧瓶中, 溶解后在三口烧瓶中加入 $2.8 \mathrm{~g}$ 三聚氭胺、5.5 $\mathrm{mL}$ 甲醛溶液, 磁力搅拌使其均匀溶解. 将水浴锅升温 到 $40{ }^{\circ} \mathrm{C}$, 在三口烧瓶中加入 $1.2 \mathrm{~mL}$ 盐酸, 搅拌条件下

图 6 基于 MFC-SDS30 对称型 $\mathrm{SCs}$ 在 $2.0 \mathrm{~mol} \cdot \mathrm{L}^{-1} \mathrm{H}_{2} \mathrm{SO}_{4}$ 中的电化学性能图: (a) 在 $10 \sim 100 \mathrm{mV} \cdot \mathrm{s}^{-1}$ 下的 $\mathrm{CV}$ 曲线, (b) 在 $0.5 \sim 10.0 \mathrm{~A} \cdot \mathrm{g}^{-1}$ 时的 $\mathrm{GCD}$ 曲线, (c) Nyquist 图, (d) 在不同电流密度下的 $C_{\mathrm{sp}}$ 值, (e) 电极材料 MFC-SDS30 在 $10 \mathrm{~A} \cdot \mathrm{g}^{-1}$ 下的循环稳定性能, (f) 基于 MFC-SDS30 的对称型 SCs 的 Ragone 图(功率密度 vs. 能量密度)

Figure 6 Electrochemical performance of the MFC-SDS30 symmetric SCs in $2.0 \mathrm{~mol} \cdot \mathrm{L}^{-1} \mathrm{H}_{2} \mathrm{SO}_{4}$ : (a) $\mathrm{CV}$ curves at $10 \sim 100 \mathrm{mV} \cdot \mathrm{s}^{-1}$, (b) $\mathrm{GCD}$ curves at $0.5 \sim 10.0 \mathrm{~A} \cdot \mathrm{g}^{-1}$, (c) Nyquist plots, (d) the $C_{\mathrm{sp}}$ at different current densities, (e) cycle stability at $10 \mathrm{~A} \cdot \mathrm{g}^{-1}$ of MFC-SDS30, (f) Ragone plot of symmetrical SCs based on MFC-SDS30 (power density vs. energy density) 
反应 $60 \mathrm{~min}$ 后得到白色悬浊液, 用无水乙醇和去离子水 反复离心洗涤, 直到 $\mathrm{pH}$ 值变为中性. 将产品冷冻干燥 $12 \mathrm{~h}$, 得到白色粉末, 命名为 MF-SDS30. 同样的, 将不 加 SDS 得到的样品命名为 MF-0.

将 MF-SDS30 置于管式炉中, 在 $\mathrm{Ar}$ 保护下缓慢升 温至 $700{ }^{\circ} \mathrm{C}$, 升温速率为 $2{ }^{\circ} \mathrm{C} \cdot \mathrm{min}^{-1}$, 保温 $3 \mathrm{~h}$. 自然冷 却至室温, 得到的样品标记为 MFC-SDS30. 同样地, 改 变 SDS 的用量(分别为 $0 \mathrm{~g} 、 0.20 \mathrm{~g} 、 0.40 \mathrm{~g}$ ), 重复上述实 验过程, 分别得到 MFC-0、MFC-SDS20 以及 MFC-SDS40.

\section{2 主要实验试剂与仪器}

三聚氰胺(国药集团化学试剂有限公司)、甲醛溶液 (烟台远东精细化工有限公司)、稀盐酸(天津市富宇精细 化工有限公司)、十二烷基硫酸钠(天津市大茂试剂有限 公司), 以上试剂均为分析纯.

集热式恒温加热磁力搅拌器(郑州予华仪器制造有 限公司); 冷冻干燥机(济南普森仪器有限公司); 开启式 真空/气氛管式电炉 (天津市中环电炉公司); 扫描电镜 (SEM，S-4800, 日本日立公司); 透射电镜 (TEM, JEM-2100, 日本电子株式会社); $\mathrm{X}$ 射线衍射仪(XRD, D8-ADVANCE，德国布鲁克公司); 拉曼光谱(Raman, Lab RAM HR800, 法国 HORIBA Jobin Yvon 公司); 傅 里叶变换红外光谱(FTIR, TENSOR 27, 德国布鲁克公 司); 热重分析(TGA, TG7, 美国 Perkin-Elmer 公司); 电 化学工作站(CHI600E, 上海辰华仪器有限公司); X 射线 光电子能谱 (XPS, Thermo ESCALAB 250XI, 美国 Thermo Fisher Scientific 公司).

\section{3 电化学性能测试}

采用三/两电极电池体系对制备的系列电极材料在 $2.0 \mathrm{~mol} \cdot \mathrm{L}^{-1} \mathrm{H}_{2} \mathrm{SO}_{4}$ 水溶液电解质中的电化学性能进行测 试. 以 MFC-SDS30 为例, 按照 $8: 1: 1$ 的质量比例称取 MFC-SDS30、导电剂乙炔黑、粘结剂聚偏氟乙烯, $N$-甲 基吡咯烷酮为溶剂, 混合均匀得到浆料, 将该浆料均匀 涂覆在不锈钢网集流体上，在 $60{ }^{\circ} \mathrm{C}$ 烘箱中干燥 $4.0 \mathrm{~h}$.

采用铂片电极和标准甘采电极分别作为对电极和 参比电极, 利用 CHI660E 电化学工作站对循环伏安 $(C V)$ 、恒流充放电(GCD)和电化学阻抗谱(EIS)进行测试.

\section{References}

[1] Díez, N.; Mysyk, R.; Zhang, W.; Goikolea, E.; Carriazo, D. J. Mater. Chem. A 2017, 5, 14619.

[2] Li, H.; Gong, Y.; Fu, C.; Zhou, H.; Yang, W.; Guo, M.; Li, M.; Kuang, Y. J. Mater. Chem. A 2017, 5, 3875.

[3] Kwon, H.; Han, D. J.; Lee, B. Y. RSC Adv. 2020, 10, 41495.

[4] Shinde, P. A.; Khan, M. F.; Rehman, M. A.; Jung, E.; Pham, Q. N.; Won, Y.; Jun, S. C. CrystEngComm 2020, 22, 6360.

[5] Du, J.; Liu, L.; Yu, Y.; Qin, Y.; Wu, H.; Chen, A. Nanoscale 2019, $11,4453$.

[6] Zhang, N.; Liu, F.; Xu, S.; Wang, F.; Yu, Q.; Liu, L. J. Mater. Chem. A 2017, 5, 22631.

[7] Yao, L.; Lin, J.; Yang, H.; Wu, Q.; Wang, D.; Li, X.; Deng, L.; Zheng, Z. Nanoscale 2019, 11, 11086.
[8] Benzigar, M. R.; Talapaneni, S. N.; Joseph, S.; Ramadass, K.; Singh, G.; Scaranto, J.; Ravon, U.; Al-Bahily, K.; Vinu, A. Chem. Soc. Rev. 2018, 47, 2680.

[9] Du, J.; Liu, L.; Yu, Y.; Lv, H.; Zhang, Y.; Chen, A. J. Mater. Chem. A 2019, 7, 1038.

[10] Yang, X.; Xu, J.; Chen, X. Chinese J. Chem. 2020, 38, 353.

[11] Xie, L.; Su, F.; Xie, L.; Guo, X.; Wang, Z.; Kong, Q.; Sun, G.; Ahmad, A.; Li, X.; Yi, Z.; Chen, C. Mater. Chem. Front. 2020, 4, 2610.

[12] Bi, R.; Mao, D.; Wang, J.; Yu, R.; Wang, D. Acta Chim. Sinica 2020, 78,1200 (in Chinese). (毕如一, 毛丹, 王江艳, 于然波, 王丹，化 学学报, 2020, 78, 1200.)

[13] Liu, Z.; Du, Z.; Xing, W.; Yan, Z. Mater. Lett. 2014, 117, 273.

[14] Wang, C.; Wu, D.; Wang, H.; Gao, Z.; Xu, F.; Jiang, K. J. Power Sources 2017, 363, 375.

[15] Li, G.; Mao, K.; Liu, M.; Yan, M.; Zhao, J.; Zeng, Y.; Yang, L.; Wu, Q. Adv. Mater. 2020, 32, 2004632.

[16] Nasini, U. B.; Bairi, V. G.; Ramasahayam, S. K.; Bourdo, S. E.; Viswanathan, T.; Shaikh, A. U. J. Power Sources 2014, 250, 257.

[17] Tutunchi, A.; Kamali, R.; Kianvash, A. J. Adhesion 2015, 91, 663.

[18] Li, M.; Zhang, Y.; Yang, L.; Liu, Y.; Yao, J. Electrochim. Acta 2015, 166,310 .

[19] Fic, K.; Lota, G.; Frackowiak, E. Electrochim. Acta 2011, 1333, 206.

[20] Kailasam, K.; Jun, Y.; Katekomol, P.; Epping, J.; Hong, W.; Thomas, A. Chem. Mater. 2010, 22, 428.

[21] Zhang, H.; Wang, Y.; Liu, C.; Jiang, H. J. Alloy. Compd. 2012, 517, 1.

[22] Yang, J.; Zhai, Y.; Deng, Y.; Gu, D.; Li, Q.; Wu, Q.; Huang, Y.; Tu, B.; Zhao, D. J. Colloid Interface Sci. 2010, 342, 579.

[23] Li, W.; Li, B.; Shen, M.; Gao, Q.; Hou, J. Chem. Eng. J. 2020, 384, 123309.

[24] Fic, K.; Lota, G.; Frackowiak, E. Electrochim. Acta 2010, 55, 7484.

[25] Liu, F.; Wang, Z.; Zhang, H.; Jin, L.; Chu, X.; Gu, B.; Huang, H.; Yang, W. Carbon 2019, 149, 105.

[26] Zhu, D.; Jiang, J.; Sun, D.; Qian, X.; Wang, Y.; Li, L.; Wang, Z.; Chai, X.; Gan, L.; Liu, M. J. Mater. Chem. A 2018, 6, 12334.

[27] Mahbub, S.; Molla, M. R.; Saha, M.; Shahriar, I.; Hoque, M. A.; Halim, M. A.; Rub, M. A.; Khan, M. A.; Azum, N. J. Mol. Liq. 2019, 283,263

[28] Kim, J. H.; Ko, Y.; Kim, Y. A.; Kim, K. S.; Yang, C. J. Alloy. Compd. 2021, 855, 157282.

[29] Pang, Z.; Li, G.; Zou, X.; Sun, C.; Hu, C.; Tang, W.; Ji, L.; Hsu, H.; $\mathrm{Xu}, \mathrm{Q}$.; Lu, X. J. Energy Chem. 2021, 56, 512.

[30] Zheng, C.; Qian, W.; Cui, C.; Zhang, Q.; Jin, Y.; Zhao, M.; Tan, P. Carbon 2012, 50, 5167.

[31] Shan, Q.; Huo, W.; Shen, M.; Jing, C.; Peng, Y.; Pu, H.; Zhang, Y. Chinese Chem. Lett. 2020, 31, 2245.

[32] Liu, X.; Lai, C.; Xiao, Z.; Zou, S.; Liu, K.; Yin, Y.; Liang, T.; Wu, Z. ACS Appl. Energ. Mater. 2019, $2,3185$.

[33] Sevilla, M.; Fuertes, A. B. ACS Nano 2014, 8, 5069.

[34] Bo, X.; Xiang, K.; Zhang, Y.; Shen, Y.; Chen, S.; Wang, Y.; Xie, M.; Guo, X. J. Energy Chem. 2019, 39, 1.

[35] Zhang, H.; Wang, B.; Yu, X.; Li, J.; Shang, J.; Yu, J. Angew. Chem Int. Ed. 2020, 132, 19558 .

[36] Du, W.; Wang, X.; Zhan, J.; Sun, X.; Kang, L.; Jiang, F.; Zhang, X.; Shao, Q.; Dong, M.; Liu, H.; Murugadoss, V.; Guo, Z. Electrochim. Acta 2019, 296, 907.

[37] Yang, G.; Wang, Y.; Zhou, S.; Jia, S.; Xu, H.; Zang, J. J. Mater. Sci. 2019, 54, 2222.

[38] Benzigar, M. R.; Talapaneni, S. N.; Joseph, S.; Ramadass, K.; Singh, G.; Scaranto, J.; Ravon, U.; Al-Bahily, K.; Vinu, A. Chem. Soc. Rev. 2018, 47, 2680.

[39] Wang, G.; Zhang, L.; Zhang, J. Chem. Soc. Rev. 2012, 41, 797.

[40] Ma, F.; Sun, L.; Zhao, H.; Li, Q.; Huo, L.; Xia, T.; Gao, S. Chem. Res. Chinese U. 2013, 29, 735.

[41] Feng, J.; Ye, S.; Lu, X.; Tong, Y.; Li, G. ACS Appl. Mater. Inter. 2015, 7, 11444.

[42] Deng, Y.; Xie, Y.; Zou, K.; Ji, X. J. Mater. Chem. A 2016, 4, 1144.

[43] Li, M.; Zhang, Y.; Yang, L.; Liu, Y.; Yao, J. Electrochim. Acta 2015, 166,310 .

[44] Wei, T.; Wei, X.; Yang, L.; Xiao, H.; Gao, Y.; Li, H. J. Power Sources 2016, 331, 373.

[45] Wang, J.; Liu, H.; Sun, H.; Hua, W.; Wang, H.; Liu, X.; Wei, B. Carbon 2018, 127, 85.

[46] Chen, H.; Zhou, M.; Wang, Z.; Zhao, S.; Guan, S. Electrochim. Acta 2014, 148, 187

[47] Liu, Y.; Cao, L.; Luo, J.; Peng, Y.; Ji, Q.; Dai, J.; Zhu, J.; Liu, X. 
ACS Sustain. Chem. Eng. 2019, 7, 2763.

[48] Miao, L.; Zhu, D.; Liu, M.; Duan, H.; Wang, Z.; Lv, Y.; Xiong, W.; Zhu, Q.; Li, L.; Chai, X.; Gan, L. Electrochim. Acta 2018, 274, 378.

[49] Díez, N.; Sevilla, M.; Fuertes, A. B. ChemElectroChem 2020, 7, 3798.

[50] Zhu, J.; Yang, J.; Miao, R.; Yao, Z.; Zhuang, X.; Feng, X. J. Mater. Chem. A 2016, 4, 2286

[51] Wang, H.; Yi, H.; Zhu, C.; Wang, X.; Fan, H. Nano Energy 2015, 13, 658.
[52] Zhao, Y.; Lu, M.; Tao, P.; Zhang, Y.; Gong, X.; Yang, Z.; Zhang, G.; Li, H. J. Power Sources 2016, 307, 391.

[53] Zhao, J.; Gong, J.; Li, Y.; Cheng, K.; Ye, K.; Zhu, K.; Yan, J.; Cao, D.; Wang, G. Acta Chim. Sinica 2018, 76, 31 (in Chinese). (赵婧, 枈俊伟, 李一举, 程魁, 叶克, 朱凯, 间俊, 曹殿学, 王贵领, 化 学学报, 2018, 76, 31.)

(Cheng, B.) 